Saudi Journal of Medical and Pharmaceutical Sciences

Abbreviated Key Title: Saudi J Med Pharm Sci

ISSN 2413-4929 (Print) |ISSN 2413-4910 (Online)

Scholars Middle East Publishers, Dubai, United Arab Emirates

Journal homepage: https://saudijournals.com

Original Research Article

\title{
An Assessment of Utilization of Oral Glucocorticoids
}

\author{
Nimmy N John", Asish Valath, Christy Varghese C and H. Doddayya
}

N.E.T Pharmacy College, Raichur- 584103, Karnataka, India

\begin{tabular}{|c|c|}
\hline DOI: $10.36348 /$ simps.2021.v07i02.002 & | Received: $19.01 .2021 \mid$ Accepted: $01.02 .2021 \mid$ Published: 04.02.2021 \\
\hline
\end{tabular}

*Corresponding author: Mrs. Nimmy N John

\section{Abstract}

Choice of glucocorticoids alongside its dose and duration are the significant angles which should be thought of while prescribing to the critically ill hospitalized patients. The reason for this examination was to get information on the current prescribing pattern of Glucocorticoids in-understanding at a tertiary care teaching hospital with an extreme objective to advance fitting utilization of glucocorticoid. An observational investigation, directed for a time of a half year from September 2019 to February 2020 in Navodaya Medical College, Hospital and Research Center (NMCH\&RC) Raichur. The current investigation was done in patients old enough 18 or above and of either sex who were endorsed with Glucocorticoid. All the new cases with glucocorticoid given was taken for the examination. Patients who were under 18 , ICU patients, lactating and pregnant ladies were prohibited from the examination. All the gathered information was dissected with the assistance of standard rules. In the current examination, the recommendation of glucocorticoids is discovered to be proper around $78 \%$. Nonetheless, to guarantee protected, compelling, and even helpful administration with glucocorticoids, the two patients and prescribers should be more mindful of the fitting portion, measurement routine, course of organization, the span of treatment and generally speaking rules for glucocorticoids recommending. Subsequently the inclusion of clinical drug specialists in clinical practice assists with expanding appropriate utilization of glucocorticoids and ideal result.

Keywords: Prescribing pattern, glucocorticoids, corticosteroids, appropriateness, inappropriateness.

Copyright (C) 2021 The Author(s): This is an open-access article distributed under the terms of the Creative Commons Attribution 4.0 International License (CC BY-NC 4.0) which permits unrestricted use, distribution, and reproduction in any medium for non-commercial use provided the original author and source are credited.

\section{INTRODUCTION}

These drug utilization evaluation (DUE) is considered as an authorized, structured, ongoing review of prescribing, dispensing and use of medication [1]. DUE can be applied to a drug, therapeutic class, disease state or a condition, a drug use process or specific outcome. DUE aides in distinguishing the issues in medication use, decrease unfavorable medication responses, advancing the medication treatment, etc [2].

In people, cortisol (hydrocortisone) is the primary glucocorticoid and aldosterone is the principal mineralocorticoid. Glucocorticoid showed in a wide assortment of conditions. Any place conceivable oral course is favored however parenteral dosages might be utilized if the sickness is extreme or a crisis emerges. Intravenous treatment is commonly utilized for escalated crisis treatment as the beginning of activity is moderately quick.

Glucocorticoids are pleiotropic hormones generally endorsed in current medication. Clinically, a few methods of Glucocorticoid administration are utilized, contingent upon the illness cycle, the organ in question, and the degree of association. GC has explicit and vague impacts that are identified with various instruments of activities, including anti-inflammatory, immunosuppressive, antiproliferative, and vasoconstrictive effects [3].

Corticosteroids are versatile in their mode of application. They can be given orally, injected into the vein or muscle, applied locally to the skin and injected directly into inflamed joints. ${ }^{3}$ Parameters that should be persistently checked during the organization of glucocorticoids are pulse, blood glucose level, serum electrolytes, and body weight [4].

Some of the recent studies conducted proved the occurrence of steroid induced hyperglycaemia among the non- diabetic hospitalized patients [5]. Also, a study led among geriatric patients shows the event of glucocorticoid induced hypertension in older patients and is more in like manner in patients with a positive family background of hypertension. Studies directed among the asthmatic patient getting glucocorticoid treatment showed low viability of glucocorticoids in obese and overweight asthmatic patient $[6,7]$. Selection of glucocorticoids along with its dose and duration are 
the important aspects which should be considered while prescribing to the critically ill hospitalized patients.

Keeping these facts in mind a prospective observational study was carried out in a tertiary care teaching hospital to make up to generate valid data for evaluation of drug use in various pathological conditions for assessing the appropriateness of glucocorticoids prescribing with respect to dose, duration of therapy and ROA for early detection of glucocorticoid related problems and minimize complications.

\section{Materials ANd Method}

A prospective observational study was carried out for the duration of 6 months among the patients under inclusion criteria. All the Patients above 18 years of age of either sex and the patients admitted with the condition that requires oral glucocorticoid therapy were included in the study.

For data collection and documentation Patient profile form was designed which includes information on demographics of patient (e.g., Patient's name, age, gender, height, weight, date of admission and date of discharge), presenting complaints, provisional/confirmed diagnosis, oral glucocorticoid therapy given (with name of glucocorticoid, dose, duration and route of therapy) and laboratory test reports.

During the study period, medical case records of patients were reviewed for the diagnosis, glucocorticoid therapy prescribed and pattern of glucocorticoid administration. The data obtained was analysed to assess the appropriateness of glucocorticoid therapy with respect to selection, dose, duration and route of administration to that of the recommended treatment guidelines.

\section{RESUlTS AND Discussions}

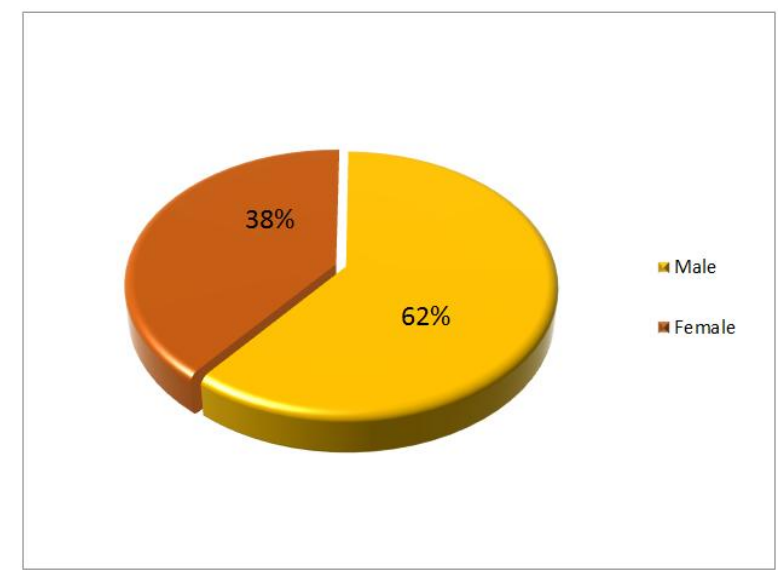

Fig-1: Gender distribution of study participants (N=93)

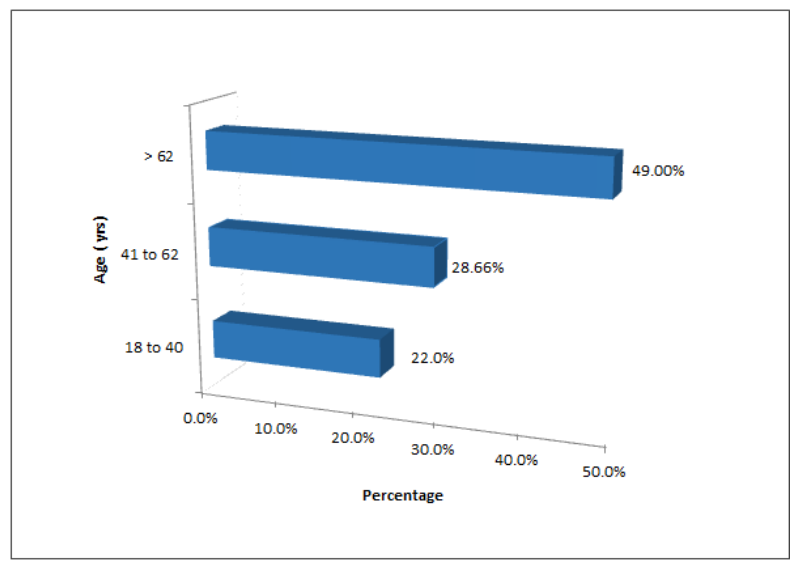

Fig-2: Age based classification of study participants (N=93)

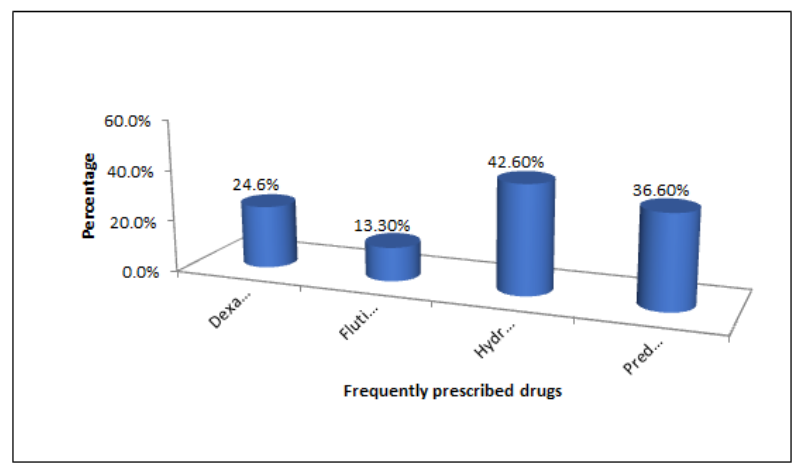

Fig-3: Frequently prescribed glucocorticoid drugs in study participants $(\mathrm{N}=93)$

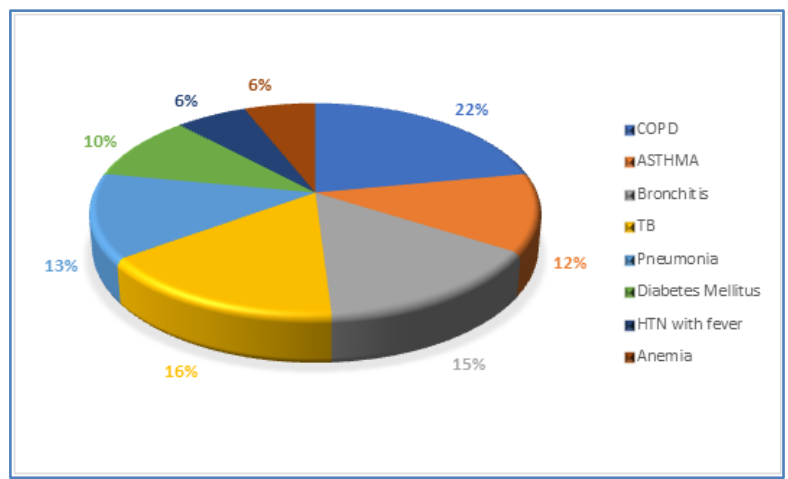

Fig-4: Disease Pattern Wise Distribution of study Population $(\mathbf{N}=93)$

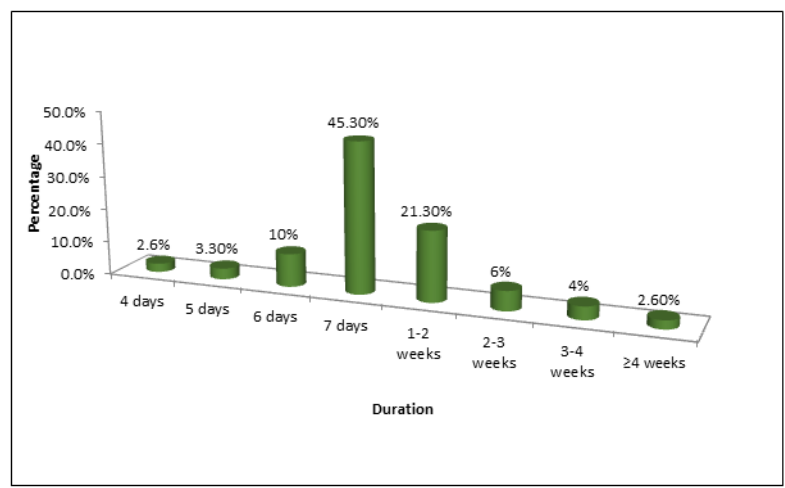

Fig-5: Duration of Treatment with Glucocorticoids in study population $(\mathrm{N}=93)$ 
Nimmy N John et al., Saudi J Med Pharm Sci, Feb, 2021; 7(2): 82-85

Table-1: Assessment of selection of glucocorticoid therapy according to dose, duration of therapy and ROA

\begin{tabular}{|c|c|c|c|c|}
\hline Drugs & Dose & $\begin{array}{c}\text { No. of } \\
\text { prescriptions }\end{array}$ & Appropriate & $\begin{array}{c}\text { Not } \\
\text { Appropriate }\end{array}$ \\
\hline \multirow[t]{2}{*}{ Dexamethasone } & $8 \mathrm{mg}$ & 1 & \multirow[t]{2}{*}{32} & \multirow[t]{2}{*}{5} \\
\hline & $4 \mathrm{mg}$ & 36 & & \\
\hline \multirow[t]{2}{*}{ Hydrocortisone } & $5 \mathrm{mg}$ & 13 & \multirow[t]{2}{*}{12} & \multirow[t]{2}{*}{7} \\
\hline & $20 \mathrm{mg}$ & 6 & & \\
\hline \multirow[t]{3}{*}{ Prednisolone } & $7.5 \mathrm{mg}$ & 12 & \multirow[t]{3}{*}{46} & \multirow[t]{3}{*}{14} \\
\hline & $30 \mathrm{mg}$ & 9 & & \\
\hline & $40 \mathrm{mg}$ & 39 & & \\
\hline \multirow[t]{2}{*}{ Methylprednisolone } & $16 \mathrm{mg}$ & 3 & \multirow[t]{2}{*}{10} & \multirow[t]{2}{*}{3} \\
\hline & $32 \mathrm{mg}$ & 10 & & \\
\hline Deflazacort & $6 \mathrm{mg}$ & 6 & 6 & 0 \\
\hline \multicolumn{2}{|l|}{ Total } & 135 & 106 & 29 \\
\hline \multicolumn{3}{|l|}{ Percentage } & $78.52 \%$ & $21.48 \%$ \\
\hline
\end{tabular}

A total of 93 patients were admitted to hospital during six month of study period with indication for oral glucocorticoid therapy. Among 93 patients included in the study comprise of 56 male and 45 female patients (fig 1). Most of patients were of age group above 62 (48\%), then followed by age group 41$62(29 \%), 18-40$ (22\%) (fig 2). Maximum number of patients was admitted in the pulmonary ward (44\%), general medicine (31\%), and ortho ward (24\%). Among all the glucocorticoids, Hydrocortisone was prescribed in maximum number of cases $(43 \%)$ as oral glucocorticoid. Prednisolone was second most prescribed (36\%) followed by Dexamethasone $(24 \%)$ as shown in figure 3 . Among all the clinical complaints, the patients were more presented with COPD 20 (22\%), followed by TB 15 (16\%), Bronchitis 14 (15\%), Pneumonia 12 (13\%), Asthma 11 (12\%), Diabetes Mellitus $10(10 \%)$, Anemia $6(6 \%)$, and HTN with fever $5(5 \%)$ (Fig.4). The duration of treatment with glucocorticoids was mainly found to be seven days in $45.3 \%$ patients, followed by $1-2$ weeks in $21.3 \%$ patients, six days in $10 \%$ patients, four days in $2.6 \%$ patients, 2-3 weeks in $6 \%$ patients, 3-4 weeks in $4 \%$ patients, five days in $53.3 \%$ patients and greater than or equal to 4 weeks in $2.6 \%$ patients (Fig. 5).

In our study we found that $78.52 \%$ of glucocorticoids were prescribed appropriately while $21.48 \%$ of glucocorticoids were prescribed inappropriately which are totally not recommended for the specific disease conditions as per the recommended guidelines. Which is shown in Table 1. Overall, 93 prescriptions were analyzed for assessing the selection of glucocorticoids according to dose, duration of therapy and ROA with respect to disease condition. In our study we found that $78.52 \%$ of glucocorticoids were prescribed appropriately while $21.48 \%$ of glucocorticoids were prescribed inappropriately which are totally not recommended for the specific disease conditions as per the recommended guidelines. The same is shown in Table.1. Results showed inappropriate prescribing of Hydrocortisone in 7 prescriptions in cases of DM and COPD. In few patients with diabetes, hydrocortisone was given for longer duration which is not recommended as they reduce sensitivity of the cells to insulin and consequently results in accumulation of glucose in blood and causes drug induced hyperglycemia and worsens the patient condition. In few patients with COPD, hydrocortisone was prescribed inappropriately with respect to ROA. Oral hydrocortisone was prescribed which is not recommended according to GOLD and WHO guidelines for management and treatment of COPD. Instead, hydrocortisone must be given systemically for increasing efficacy of treating the condition.

In some cases of $\mathrm{DM}, \mathrm{TB}$ and anemia prednisolone was inappropriately prescribed in 14 prescriptions. In few patients with TB prednisolone was prescribed which interacts with anti-tubercular drugs mainly rifampicin and this interaction results in reducing effectiveness of prednisolone. So, it is recommended to avoid prednisolone prescribing in TB cases and prescribe a glucocorticoid which does not interact with anti-tubercular drugs. In few anemic cases prednisolone was prescribed for reducing hemolysis of anemia but duration of therapy was only for 1-2 weeks and after that drug was immediately stopped. It is not advisable to stop prednisolone at once instead the prednisolone dose should be gradually and slowly tapered off for avoiding withdrawal effects. In few patients with DM prednisolone was given for longer period of time i.e., for 7 days which is inappropriate because prednisolone rises the blood sugar level within 2 days. So, it is advisable not to give prednisolone for longer duration as it results in worsening the diabetic condition of patients. In cases of HTN with fever dexamethasone was inappropriately prescribed in 5 prescriptions. Dexamethasone is a potent glucocorticoid which causes sodium retention in kidney and results in volume expansion and subsequent increase in blood pressure. So, it is advisable to avoid prescribing 
glucocorticoids in HTN cases as it results in glucocorticoid induced HTN and worsens the condition of patient who is already hypertensive.

However, to ensure safe, effective and wellbalanced therapeutic management with glucocorticoids, both patients and prescribers should be more aware of the appropriate dose, dosage regimen, route of administration, duration of therapy and overall guidelines for glucocorticoids prescribing. Hence the involvement of clinical pharmacists in clinical practice helps to increase proper usage of glucocorticoids and optimum outcome.

\section{CONCLUSION}

GCs though they are life-saving drugs, produce adverse reactions which may be mild or life threatening. Considerable attention should be given to relative risks \& benefits, benefits definitely outweighing the risks \& individualization of treatment is necessary. The decision to use Glucocorticoids should be made when a presumptive diagnosis has been made \& when available information suggests a reasonable possibility of benefit. Criteria to use should be clearly identified and should be objective or quantifiable. To achieve better patient care, there is need to monitor, evaluate and therapeutically analyze the utilization pattern of glucocorticoids. Such analysis will not only improve the standards of medical treatment at all levels in health system, but will also help in the identification of problems related to drug use such as polypharmacy, drug-drug interaction and adverse drug reactions. Standard treatment guideline should be developed at all hospitals for prescribing of glucocorticoids taking into consideration the patient specific parameters which will improve therapeutic outcomes.

\section{ACKNOWLEDGEMENT}

Authors take it as a privilege to acknowledge Sri S R Reddy; Chairman Navodaya Educational Trust, Medical Superintendent; Navodaya Medical College Hospital and Research Centre, Principal; N.E.T
Pharmacy College, HODs of department of Pharmacy practice and Medicine department and the staffs for their support during the study. Special thanks to Mr. Bhaskar, Biostatician, for his valuable guidance and suggestions throughout our project work.

\section{REFERENCE}

1. Thadanki, M., Kumar, C. P., Tejaswi, M., Baburao, R., \& Charitha, K. (2019). Drug utilisation evaluation of corticosteroids in tertiary care theaching hospital. IJPSR, 10(3), 1468-76.

2. Asha, P. (2015). Drug Utilization Evaluation of Corticosteroids Based on Safety: A Prospective Observational Study. International Journal, 6(1), 1591-1597.

3. Bertram, G. Katzung, Basics and clinical pharmacology, 10th edition, chapter 39.

4. Lacy, C.F., Armstrong, L.L., Goldman, M.P., Lance, L.L., (Eds.). (2009-2010). Drug Information Handbook. $18^{\text {th }}$ ed. Lexi-Comp Publication. 396,701,1147,916

5. Dave, P., Raut, A., Diwan, A. (2011). A Prospective Study of Steroid induced Hyperglycemia. Journal of Medical Science and Research (JMSR); 2(1): 46-9.

6. Steroids Not as Effective in Obese Asthma Patients. [cited on 11 Apr 2012] Available from:http://www.nationaljewish.org/about/mediace nter/pressreleases/2008/steroids-not-as-effectivein-overweight-asthma-patients

7. Sato, A., Funder, J.W., Okubo, M. (1995). Glucocorticoid-induced hypertension in the elderly relation to serum calcium and family history of essential hypertension. American Journal of Hypertension, 8:823-8.

8. Haynes, R.C. (1992). "Adrenocorticotrophic hormone, adrenocortical steroids and their synthetic analogues". Gilman AG, Hardman JG, Limbird LE (Eds.). Goodman and Gilman's "The Pharmacological basis of Therapeutics". vol.2, $11^{\text {th }} \quad$ ed., Newyork, MC Graw Hill; chapter 59; 1432. 